\title{
Aspectos antropológicos para a evangelização junto às Juventudes: reflexões a partir do Sínodo dos Bispos de 2018
}

\author{
Anthropological aspects for evangelization \\ with the Youth: reflections from the Synod \\ of Bishops of 2018
}

\author{
Joel Portella Amado
}

\section{Resumo}

$\mathrm{O}$ artigo apresenta, sob a ótica da antropologia teológica, o desafio evangelizador junto à(s) juventude(s) atual(ais), marcada(s) pela mudança de época. Inicia, portanto, com algumas características do atual momento histórico, nele contextualizando, em seguida, as questões ligadas à juventude. Num terceiro momento, contextualiza o Sínodo dos Bispos de 2018, que trata dos jovens. Em seguida, recorda a importância antropológica de alguns conceitos essenciais para o cristianismo: pessoa, alteridade e gratuidade, para, ao final, apresentar seis indicações pastorais que não podem ser deixadas de lado no atual momento evangelizador com os jovens.

Palavras-chave: Juventude. Sínodo dos Bispos. Sentido da vida. Evangelização. Desafios pastorais.

\section{Abstract}

The article presents, from the perspective of theological anthropology, the challenge of evangelization with youth(s) nowadays, which is characterized 
by the change of era. It begins, therefore, with some characteristics of the current historical moment, presenting some questions related to the youth. In a third moment, it contextualizes the Synod of Bishops of 2018, which aim is exactly young people. It then recalls the anthropological importance of some essential Christian concepts: person, otherness and gratuitousness, in order to finally present six pastoral indications that cannot be overlooked in the current evangelizing moment with young people.

Keywords: Youth. Synod of Bishops. Meaning of life. Evangelization. Pastoral challenges.

\section{Introdução}

Os jovens sempre foram objeto de estudo das mais variadas ciências, dentre as quais a teologia pastoral e a antropologia teológica. Com o passar do tempo, mais do que objetos no sentido passivo do termo, tem-se reconhecido que, nestes estudos, os jovens podem e devem ser sujeitos das reflexões desenvolvidas a seu respeito. Ao longo de sua história, a Igreja tem não apenas dado atenção aos jovens, como também, nesta atenção, buscado compreender o que eles sentem e pensam. A partir do Vaticano II, esta compreensão também se tem realizado nos Sínodos dos Bispos. Em 2018, o tema foi exatamente a juventude, com um enfoque bastante específico, a saber, "Os jovens, a fé e o discernimento vocacional".

Subjacente à temática da fé e do discernimento vocacional, encontrase um dos maiores desafios de nosso tempo, a saber, o de estabelecer e firmar a identidade dentro do que se convencionou chamar a questão do sentido. Não se trata, portanto, de considerar os termos fé e discernimento vocacional no sentido de encontrar pedagogias para um catecismo válido em outros tempos nem de investir no despertar de candidatos para o sacerdócio. Por certo, há de se atuar catequeticamente assim como desenvolver o trabalho da pastoral vocacional. No entanto, o Sínodo de 2018 nos interpela a ampliar nosso horizonte pastoral para as bases antropológicas e socioculturais sobre as quais se vai desenvolver qualquer ação evangelizadora com os jovens. Reconhecendo o valor do trabalho pastoral feito até então, o Sínodo dos Bispos 2018, ao propor as questões da fé da vocação, coloca-as na perspectiva da questão humana pelo sentido 
da existência, uma questão emergencial em tempos históricos de fortíssima transformação.

Os jovens de nossos dias nasceram e estão amadurecendo num ambiente tecnológico e cultural para o qual o próprio mundo e, nele, a ação evangelizadora experimentam significativa dose de perplexidade. São mudanças ao mesmo tempo rápidas e profundas, exigindo, por isso, que se pare a fim de escutar e refletir com e sobre os jovens. Ao mesmo tempo em que procura se compreender neste mundo em mutação, a Igreja percebe a urgência do desafio de transmitir a fé às novas gerações e, em espírito de serviço à humanidade, ajudar estas mesmas gerações a firmar o passo, na construção de um mundo capaz de enfrentar as sequelas humanas, sociais, culturais, morais e ambientais construídas nos últimos séculos. Deste modo, embora estejamos diante de um Sínodo que trata especificamente dos jovens, temos a possibilidade de pensar a ação evangelizadora como um todo, ainda que de modo indutivo, a partir de uma realidade bastante desafiadora, na medida em que vive de modo mais agudo o que todos experimentam em algum nível.

\section{O ponto de partida}

Independentemente dos enfoques dados às reflexões a respeito da juventude e das expectativas em relação ao Sínodo dos Bispos de 2018, não se pode negar que tanto as reflexões quanto o Sínodo tiveram que considerar o fato de que estamos todos envolvidos na tarefa de encontrar outros rumos para o mundo como um todo. A experiência dos esgotamentos cresce a cada dia. São esgotamentos dos recursos ambientais. São esgotamentos humanos, com crescentes índices de depressão sob variadas formas, chegando ao extremo do crescente número de suicídios, em especial junto aos jovens. São esgotamentos humanitários, onde o contraste entre o desenvolvimento tecnológico, por um lado, e o crescer da miséria e da exclusão, por outro, nos interpelam. Todos esses colapsos apontam para uma situação de fundo que já vem sendo alertada há algum tempo. Estudiosos de várias ciências, líderes religiosos, gente simples cujos nomes não aparecem nas publicações gabaritadas, cada um(a), enfim, ao seu jeito, tem acenado para a crise de fundo a todas as demais crises, a saber, a crise do sentido, do significado global da existência e, nela, dos significados parciais. ${ }^{1}$ Perguntas do tipo "de que país precisamos" ou "o que

${ }^{1}$ BAUMAN, Z., O mal-estar da pós-modernidade, p. 142ss; UMBELINO, L. A., Crise e sentido, p. 57-70. 
entendemos por justiça" e outras tantas apontam para a questão do significado global da existência de pessoas e de povos, nisso incluindo o planeta como um todo. A pergunta pelo sentido se torna desse modo uma pergunta humana, social e ambiental.

Em tudo isso, identificamos o esgotamento da modernidade enquanto concepção do sujeito individual voltado predominantemente para si, com relacionamentos de contorno predominantemente funcional. Nosso mundo, ainda que em graus diferentes de afetação, experimenta o oscilar de posturas, compreensões e consequentes atividades. Entre os extremos da indiferença e da radicalização, percebemos uma grande variedade de compreensões, num mosaico em contínua mutação, sem que alguns aspectos obtenham a condição de referências irrenunciáveis. Por certo, não se trata de retornar a períodos históricos anteriores, mas de reconhecer que, no quadro aqui resumido, é humana e socialmente indispensável obter um mínimo de critérios para a resposta à questão do sentido. Reiterando o que tanto já se tem falado, há de se pensar, portanto, na questão da juventude em chave de mudança de época.

Nosso mundo tem se marcado por mobilidade, pluralidade, diversidade e aleatoriedade, entre outras características, exigindo que se coloque a pergunta pela viabilidade de um mundo construído sobre estas perspectivas. Nosso mundo tem igualmente sido atingido por algumas situações que interpelam quem se dedica a pensar sobre o que diz respeito ao ser humano, exigindo atenção especial às crescentes sequelas humanitárias. Nosso mundo, por fim, tem experimentado reações indicadoras de busca dos novos rumos, solicitando, portanto, maior atenção e mesmo estímulo.

No primeiro caso, podemos resumi-lo a partir do termo mobilidade, pois não se trata apenas do surgimento de possibilidades diferentes e divergentes, num mundo plural e diversificado, mas do modo como se lida com essa condição de multiplicidade. Tantas são as possibilidades que, mais do que permanecer numa única, a contínua migração, num processo de ininterrupta experimentação, acaba se tornando regra maior, a partir da qual se explica até mesmo o extremo oposto, isto é, o fundamentalismo em suas variadas concretizações. De tanto precisar experimentar, acaba-se escolhendo fixar num ponto de vista, dele não abrindo mão nem mesmo nos menores detalhes, evidentemente secundários. Mais, portanto, do que a pluralidade em si, enquanto existência de diferentes caminhos para a compreensão do sentido, o que se tem é uma espécie de imperativo da mobilidade, para o qual não se pode permanecer numa única perspectiva. O que Peter Berger indicava antes 
como imperativo herético, ${ }^{2}$ enquanto contínua necessidade de o indivíduo não ter suas escolhas balizadas pelas instituições e tradições, tornou-se um processo mais agudo e por isso mesmo exigente, abrindo espaço para a postura diametralmente oposta, isto é, o fundamentalismo. Na verdade, indiferença e radicalização, relativismos e fanatismos, são concretizações do mesmo contexto que resumidamente podemos chamar de mobilidade.

Em meio a tudo isso, nosso mundo tem experimentado o crescimento de inúmeras formas de desumanização. Aumenta o número de pobres e excluídos assim como aumentam os modos de pobreza e exclusão. Este aumento faz com que a ação pastoral de uma igreja particular que, em outros tempos não muito distantes, se preocupava com, por exemplo, a questão da moradia, com significativos resultados neste campo, atualmente se desloque para quem possui apenas a rua como moradia. Especialmente em nossas grandes cidades, vem crescendo a população em situação de rua, num processo integrado à expansão de um comércio de drogas que já não considera mais o risco da morte da clientela, pois a reserva de compradores está tendendo a aumentar ou pelo menos se manter. Pelo mundo afora, esta população urbana em situação de rua adquire o rosto dos refugiados e apátridas, com extermínios que nos interrogam a respeito da inércia de quem poderia mudar tal quadro. No âmbito dos países, o modo como se enfrenta a questão carcerária tem revelado que estamos vivenciando a passagem do que, em décadas anteriores, se chamava de questão social para o que nos dias atuais se pode denominar como questão verdadeiramente humanitária.

Certamente, não se trata de apenas considerar as sequelas de nosso tempo, mas de também observar reações em busca de um mundo diferente. Diante da inércia ou mesmo falência de instâncias que deveriam possibilitar o enfrentamento e a resposta às grandes questões, vemos emergir iniciativas, ensaios muitas vezes tateantes, porém reveladores de que a inaceitação se faz presente e, com ela, o desejo de agir. Dentre essas tentativas de enfrentamento, destaca-se a atitude de responder às questões em primeira pessoa, não delegando para outrem as soluções, mas de agir diretamente sobre os problemas ou pelo menos sobre as consequências. Um dos exemplos mais simples é o dos grupos, religiosos ou não, que se têm dedicado ao fornecimento de alimentação noturna e agasalho para a referida população em situação de rua. É certo que no mesmo patamar dos enfrentamentos pelas próprias mãos, encontram-

${ }^{2}$ BERGER, P. L.; GORDON, F., O Imperativo Herético, p. 15-49. 
se propostas de natureza eliminatória, com a simples e imediata destruição do diferente, considerado como inimigo, como é o caso das chacinas e dos projetos de armamentismo individual. Mais do que um ou outro exemplo, de fato tão diferentes e mesmo opostos, pois o primeiro busca socorrer enquanto o outro intenta eliminar, importa destacar o desejo de agir, atuar, contribuir diretamente para a solução dos problemas.

Desse modo, se, por um lado, esta chave de leitura é sempre importante, ajudando a refletir sobre diversos aspectos, ela atinge uma importância maior quando se trata de juventude, pois, como sabemos, é a juventude que está gradativamente assumindo os rumos do mundo. As gerações anteriores fizeram sua parte, semeando valores, mas deixando efeitos colaterais. As novas gerações recebem um mundo em agudo processo de transformação, cabendolhes um papel desafiador. Daí a importância de toda reflexão sobre a juventude e, neste contexto, um sínodo dos bispos. $\mathrm{O}$ futuro do mundo depende em boa parte do modo como vamos lidar com as gerações jovens, podendo-se mesmo falar em hipoteca geracional, no sentido bem específico do tipo de mundo que estamos deixando para os que nos sucedem.

\section{Juventude, juventudes e outras perspectivas}

Estabelecido o patamar da mudança de época, importa identificar também o que se entende por jovens e juventude. Nesse campo, os estudos são inúmeros, variando de acordo com a perspectiva em que são feitos. ${ }^{3}$ Os elementos comuns para a identificação desta fase da vida encontram-se na limitação etária e na incidência sobre a personalidade. Não se discute que se trate de uma etapa da vida em que, na continuidade da adolescência, se estão fixando as características socioculturais, éticas e existenciais da pessoa. Oscilam, no entanto, as determinações etárias, isto é, em que idade se ingressa na juventude e em que idade se passa à fase adulta. É certo que limites etários não podem ser generalizados quando se quer dialogar com realidades tão diversificadas. É, no entanto, igualmente certo que algum parâmetro é necessário quando se trata de buscar entender a juventude. Em nossos dias, a tendência é a de considerar que o período da juventude, enquanto fixação das referidas características, tem se dilatado. ${ }^{4} \mathrm{Se}$ em outros momentos da história

\footnotetext{
${ }^{3}$ ABRAMO, H. W.; FREITAS, M. V.; SPOSITO, M. P., Juventude em debate; PRADO, A. R. (Org.), Cultura juvenil.

${ }^{4}$ VARGAS GIL SOUZA, C. Z., Juventude e contemporaneidade.
} 
do mundo se considerava suficiente o período de uma década, pode-se dizer que atualmente este período até mesmo se duplicou. Se, a título de exemplo, o filho foi gerado quando o pai tinha 22 anos, com profissão estabelecida ainda que em início de carreira, este mesmo filho, aos 33, ainda não definiu com clareza o que deseja para sua vida profissional, perambula por relacionamentos afetivos tênues e depende da mãe para os menores e mais imediatos serviços. Feita a ressalva de que todo exemplo é sempre limitado e mesmo exacerbado, fica a certeza de que o período denominado juventude cronologicamente se tem dilatado.

Ao mesmo tempo, um outro fenômeno tem se manifestado em relação à juventude, trata-se de sua relação com o todo social. Trata-se da transformação nas funções sociais atribuídas ao ser humano em cada etapa da vida, dentre elas a juventude. Embora permaneça uma dose de inadequação às expectativas socioculturais, as avaliações em relação à juventude de nossos dias oscilam desde o sentimento de que estão afastadas de seu papel questionador das lógicas predominantes até a intuição de que se encontram presentes em inúmeras iniciativas que buscam novos rumos para o mundo. Em face de tal oscilação, melhor será afirmar que os jovens permanecem em sua função de busca tanto da própria identidade quanto da incidência sobre o mundo. O que mudou foi o modo de buscar e de incidir, permanecendo, porém, as duas situações. Se, décadas atrás, encontrávamos jovens militando em face dos regimes de exceção, ${ }^{5}$ atualmente vemos jovens, por exemplo, buscando, nas ruas das grandes cidades, outros jovens atingidos pela dependência química e outras mazelas. Se, em outras épocas, encontrávamos jovens com suas camisetas, boinas e jeans "enfrentando canhões", ${ }^{6}$ atualmente encontramos jovens com vestes religiosas de estilo medieval, com silícios e similares, enfrentando batalhas com a espada de S. Miguel. Não são - precisamos nos perguntar - formas diferentes da mesma atitude de busca e de empenho pelo aqui tão destacado mundo diferente? É certo que, a partir do lugar sociocultural e teológico em que cada um se encontre, a resposta será diferenciada. É, todavia, igualmente certo que, tanto em razão de estarmos diante do ser humano quando em virtude da necessária isenção acadêmica, devamos aprofundar na compreensão desses fatos humanos e sociais, ultrapassando leituras mais imediatistas, com o risco de serem até mesmo preconceituosas e não leais ao real.

\footnotetext{
${ }^{5}$ BENEVIDES, S. C. O., Na contramão do poder, p. 45-70.

${ }^{6}$ SILVA, W. T.; ROCHA, D., Os anos 1960 e o horizonte utópico da juventude católica, p. 623-643.
} 
Uma terceira característica pode ainda ser acrescentada em linha de continuidade com as anteriores. Trata-se, na verdade, da concretização para a juventude das lógicas da pluralidade e diversificação. Jeans, boinas e sandálias ou visual medieval, protestos ou peregrinações, são, sob a ótica sociocultural, possibilidades oferecidas por um mundo extremamente caracterizado pela multiplicidade. É consequentemente possível em nossos dias ser jovem de diversas maneiras, com distintas configurações, a ponto de se preferir falar mais em juventudes no plural do que uma única juventude, como se fosse uma massa uniforme. Num mundo que experimenta e de certo modo valoriza a diferenciação, o uso do plural tende a ser mais fiel ao que se está vivenciando.

Estas três características não são as únicas para identificar a(s) juventude(s) contemporâneas. Elas foram escolhidas em virtude do patamar mudança de época. Desde o final da década de 1950, tem-se convencionado identificar a(s) juventude(s) a partir da terminologia alfabética. ${ }^{7}$ É por isso que se tem falado em gerações $\mathrm{Y}$ e $\mathrm{Z}$. A primeira, que recebe a letra $\mathrm{Y}$, se refere aos que se encontram entre os 21 e os 35 anos. A segunda identifica os que estão atualmente entre os 12 e os 20 anos. Feitas as ressalvas sobre a flacidez cronológica, destaca-se aqui, mais uma vez, o alargamento cronológico da condição juventude, nela se destacando, por certo, a adolescência.

$\mathrm{O}$ elemento em comum para estas duas gerações, à diferença das anteriores, tem sido identificado na relação que elas estabelecem com o mundo digital, tanto no que diz respeito especificamente à tecnologia quanto em relação à compreensão da vida. É praticamente consenso se referir a estas duas gerações como nativas digitais, ou seja, chegaram ao mundo quando os avanços da informática e a internet já estão implantados na vida e na mente. ${ }^{8}$ Estas duas gerações, bem sabemos, não conhecem um mundo sem a tecnologia atual. Foram e estão sendo endoculturadas no que se pode chamar de cibercultura, em que as noções, por exemplo, de espaço e tempo não são as mesmas vivenciadas pelas gerações anteriores. Desaparecem os limites de espaço na medida em que, com o simples digitar de um smartphone, chegase a qualquer parte do mundo. O tempo, por sua vez, não experimenta mais os limites fortemente sentidos pelas mesmas gerações anteriores. Passado e

\footnotetext{
${ }^{7} \mathrm{O}$ uso das letras, iniciado com o $\mathrm{X}$, serviu para expressar uma realidade não plenamente captável e por isso mesmo não claramente denominável. Sobre esta geração X: ULRICH, J. M.; HARRIS, A. L., GenXegesis, p. 162-198 e p. 268-296; DEVERSON, J.; HAMBLETT, C., Generation X.

${ }^{8}$ PALFREY, J.; GASSER, U., Nascidos na era digital.
} 
futuro se voltam com desafiadora força para a valorização do presente, pois tudo necessita acontecer no hoje da existência, com o risco, certamente, da desvinculação com o passado e a perplexidade diante do futuro.

Chama a atenção o que alguns estudos têm indicado a respeito da fragilidade diante da incansável busca pela novidade, na linha do que antes se chamou aqui de imperativo da mobilidade. De fato, as gerações mais recentes experienciam a necessidade de continuamente baixar novos aplicativos tanto para seus smartphones quanto para seu sentir e seu pensar. Em nosso idioma, a diferença entre ser e estar ajuda a compreender as transformações ocorridas. Mais do que ser, como característica de perenidade, importa estar como indicação de que, em pouco tempo, não se estará mais. Num contexto marcado pela ambiguidade, encontraremos quem avalie esta realidade como negativa e quem enxergue positividade. A tendência à avaliação negativa costuma integrar a fragilidade de critérios com a subordinação às lógicas do mercado, às dinâmicas do consumo. Neste caso, as fragilidades estão diretamente ligadas à predisposição para consumir. A tendência à avalição positiva visualiza a possibilidade de relativização de valores e práticas que não levam à efetiva humanização, fazendo emergir algo que é próprio do ser humano, isto é, seu contínuo caminhar na história. Trata-se, portanto, de refletir a respeito da(s) juventude(s) dentro de uma ótica de mudança de época, levando em conta a ambiguidade das situações. Este é o horizonte que nos leva ao Sínodo dos Bispos 2018.

\section{O Sínodo da Juventude}

Na história dos Sínodos dos Bispos, instância pastoral recuperada após o Concílio Vaticano II, o evento de 2018 se insere na linha de continuidade com os anteriores, tratando de temas urgentes sob o que podemos chamar de ótica da nova evangelização. Nesse sentido, é bom recordar a ligação direta entre a mudança de época como um dado de realidade e a nova evangelização como opção pastoral. É deste modo possível identificar uma linha de continuidade entre os últimos Sínodos. O de 2012 tratou exatamente da nova evangelização para a transmissão da fé. O de 2014 tratou dos desafios pastorais sobre a família no contexto da evangelização. Mesmo o Sínodo de 2019 que tratará da questão amazônica também pode ser visto sob esta mesma ótica.

No específico tema da(s) juventude(s), o documento final da reunião présinodal ocorrida em Roma, de 19 a 24 de março de 2018, com a presença 
destacada dos jovens, indicou algumas questões que, olhadas no conjunto, nos permitem perceber exatamente a relação entre juventude(s), mudança de época e nova evangelização. ${ }^{9} \mathrm{Na}$ primeira parte do referido documento, entre os "desafios e oportunidades dos jovens no mundo de hoje", destacamse: 1) a formação da personalidade; 2) a relação com as outras pessoas; 3) a específica questão do futuro; 4) a relação com a tecnologia; e 5) a busca pelo sentido da vida. Facilmente, portanto, se percebe a linha condutora da reflexão pré-sinodal. A questão de fundo permanece sendo a mais radical de todas as questões, ou seja, o sentido ou significado da existência. Num mundo que experimenta uma mudança de época, a identidade, os relacionamentos e a esperança quanto ao futuro são desdobramentos irrenunciáveis. E tudo isso deve ser enfrentado dentro de um contexto marcado pela tecnologia e pela mentalidade dela decorrente.

A formação da personalidade ou, se assim desejarmos, a questão da identidade enfrenta o impasse da ausência de fôlego das instâncias que durante longo tempo serviram para a transmissão de valores e significados. O documento pré-sinodal menciona explicitamente o declínio dos modelos tradicionais de família, com o esmorecimento das tradições e referências. Junto com a questão especificamente familiar, podemos acrescer o desbotamento das demais instituições produtoras ou alimentadoras de sentido e identidade, dentre elas as diretamente ligadas ao mundo da educação. Por sua vez, esta realidade leva ao questionamento não apenas da relação consigo mesmo(a), relação diretamente ligada à identidade, mas também às relações com as outras pessoas, segundo ponto indicado no documento pré-sinodal. Na medida em que as novas tecnologias rompem até mesmo com os limites de espaço e tempo, o círculo de contatos se amplia, abrindo um leque de possibilidades para os relacionamentos. Este fato, porém, carrega em si a mesma ambiguidade de tantos outros. Ao mesmo tempo em que purifica relacionamentos, possibilita também que não se enfrentem desajustes e dificuldades oriundas do convívio, passando-se adiante, rumo a outros contatos. A isto se acrescenta o desafio de se buscar o equilíbrio entre os relacionamentos virtuais e os presenciais. O risco de se priorizar as amizades virtuais, em detrimento, portanto, da presença física é grande e deve ser atentamente observado. Surge, desse modo, o desafio de se pensar a integração da tecnologia na vida da(s) juventude(s). Por integração, não se deve compreender apenas o acesso, negado a quem não possui plenas

${ }_{9}^{9}$ SÍNODO DOS BISPOS, Os jovens, a fé e o discernimento vocacional. 
condições de participar dos mecanismos do mercado. Na medida em que os resultados do progresso científico e tecnológico devem ser colocados a serviço de toda a humanidade, não se discute a importância de possibilitar o acesso à tecnologia, especialmente informática e internet, ainda mais se se considera que estamos falando de juventude(s) nativa(s). No entanto, é preciso indicar que integração abrange também a questão das relações, exigindo contínuo reequilíbrio no seu uso, de modo a não inverter a escala de valores entre a dimensão presencial e a virtual, a superar as dependências ou, como denomina o documento pré-sinodal, os vícios, o aproveitamento das redes sociais para a efetiva socialização e a inserção deste complexo tecnológico em processos educativos que englobem também os aspectos éticos e existenciais.

$\mathrm{Na}$ medida, portanto, em que as relações consigo mesmo(a), questão da identidade, e com as demais pessoas, questão da relacionalidade, se sentem afetadas, atinge-se igualmente a relação com o futuro, abalandose a esperança. Em termos específicos da juventude, sabemos que se trata de uma fase da vida em que se busca definição, mas também estabilidade e plenitude, termos utilizados no documento pré-sinodal. Ocorre que a ausência das instâncias apoiadoras à formação da personalidade, da fragilidade de vínculos afetivos e fraternos e o "tsunami" de possibilidades para a fruição dos recursos da tecnologia colocados à disposição por um mercado voraz, bem como os processos de empobrecimento e exclusão, tudo isso, enfim, acaba por tornar o futuro nebuloso, reduzindo as doses de esperança, notadamente o que podemos chamar de esperança ativa, aquela que leva a confiar em Deus mas também atuar para a construção do futuro. Nesse sentido, o documento pré-sinodal menciona uma situação que vem cada vez mais suscitando preocupação pastoral. Trata do que o referido documento indica como "desestabilidades mentais". ${ }^{10}$ São aspectos emocionais, relacionais, psicológicos ou afetivos. Existem muitos termos para sinonimizar a expressão adotada pelo documento. No entanto, mais do que pelejar por terminologia, importa observar que as questões existenciais devem receber a mesma consideração das sociais e ambientais. Além de a pessoa ser uma só, sem qualquer possibilidade de fatiamento, esta dimensão aqui chamada de existencial tem adquirido proeminência cronológica. Estamos num tempo de maior atenção a este aspecto. Por tudo isso, retornamos à questão pelo sentido da vida, questão diretamente ligada à

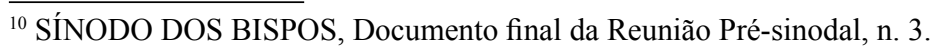


identidade e à relacionalidade, ao futuro e à esperança e ao sadio equilíbrio no uso dos bens e da tecnologia.

\section{O irrenunciável pressuposto antropológico}

A(s) juventude(s) experimenta(m), assim, um conjunto de desafios provenientes das diversas dimensões nas quais os seres humanos estão envolvidos. São, como já indicado, desafios de natureza pessoal, social, ambiental e religiosa. Dependendo do aporte dado, um ou outro desafio pode adquirir primazia, com o risco de não se considerar adequadamente os demais. Não se nega que historicamente um desafio venha a assumir destaque. Importa que destaques cronológicos não anulem as demais dimensões do ser humano, o qual deve ser sempre visto de modo integral. O ser humano experimenta-se, ao mesmo tempo, como razão e afeto, historicidade e transcendência, auto possessão e relacionamento, socioambientalidade e religião. O ser humano é tudo isso e muito mais. Sua maturidade ou, se desejarmos, sua humanização depende de sua capacidade de gradativamente articular essas dimensões no que se tem denominado como a questão do sentido. Ao mesmo tempo em que não se pode aceitar cisão no ser humano, com a primazia excludente de uma dimensão sobre as demais, tampouco se pode prescindir da questão do sentido, como questão antropologicamente abrangente e, por isso mesmo, unificadora.

O ser humano tem fome, precisa de trabalho, moradia, segurança e saúde. O ser humano necessita de relacionamentos afetivos maduros, consequentes, assim como necessita aprender cada vez mais a lidar com o meio ambiente e articular seu contato com o mistério de Deus, num caminhar contínuo e gradativo ao longo da vida. Esta é a razão pela qual uma reflexão sobre a(s) juventude(s) não pode prescindir deste pressuposto antropológico integral. É por isso que a ação evangelizadora junto à(s) juventude(s) necessita articular a questão do sentido com as diversas dimensões do ser humano. Deverá ser uma ação que ajude na integração entre a dimensão pessoal e a social, entre a ambiental e a religiosa, entre a racional e a afetiva e assim por diante. Nesta perspectiva integrada, a questão do sentido último da existência adquire reiterando - conotação indispensável.

Assim como não somos humanos fatiados, vivendo aos pedaços entre as distintas dimensões da única pessoa, tampouco somos humanos se não nos defrontamos explicitamente com a questão do sentido ou significado da existência. Trata-se, como bem sabemos, de questão universal, que, 
atravessando a história da humanidade, encontra respostas e valorações distintas. Em nossos dias, porém, esta diversidade de respostas para a questão do sentido adquire um perfil peculiar na medida em que vivenciamos intensa carga de pluralidade, com a referida possibilidade de oscilação e fechamento individualista em respostas unilaterais, imediatistas e mesmo negadoras da alteridade.

Mudanças de época são períodos históricos de busca. Por sua vez, buscas em horizonte plural exigem, ao mesmo tempo, respeito pelos pontos de vista diferentes, mas também discernimento e opção. Exigem que se firmem as identidades. Estas, por sua vez, não podem ser identidades fechadas em si, ao estilo das conhecidas mônadas, mas, ao contrário, aptas a continuamente dialogarem com pontos de vista diferentes, retornando para si, no exercício de síntese e ratificação-purificação das respostas encontradas para a questão do sentido. Identidades fechadas em si geram fundamentalismos e fanatismos que não conseguem distinguir os conteúdos das formulações. Uma identidade se firma tanto nos conteúdos quanto nas formulações, mas sua base efetiva se encontra nos conteúdos. As formulações ajudam no intercâmbio das individualidades, pois somos seres de linguagem, de comunicação. Não podem, entretanto, se identificar plenamente com os conteúdos, sob o risco de até mesmo se sobrepor a eles. Os conteúdos são experienciais, expressandose certamente em linguagens, as quais, todavia, são sempre limitadas para expressar o que se tem como resposta para a questão do sentido.

Num mundo fortemente plural, o cristianismo aparece como uma resposta à questão do sentido. Desafiado pelos mecanismos da desinstitucionalização e destradicionalização, o cristianismo experimenta o desafio da perda de plausibilidade sociocultural, necessitando, portanto, explicitar a cada momento sua identidade. A este fato, acrescenta-se ainda a pluralidade nas formas de compreender e vivenciar a pessoa e a mensagem de Jesus Cristo, em nome do qual se apresentam propostas até mesmo diametrais. Deste modo, torna-se importante não apenas focalizar a ação evangelizadora da(s) juventude(s) na questão do sentido em vista do ser humano integral, mas também explicitar qual o conteúdo que se deve dar ao encontro com Jesus Cristo e o Reino de Deus. O risco de se permanecer na beligerância de linguagens, desprezandose, ainda que de forma tácita, os conteúdos, é muito forte num tempo como o atual. De fato, contendas sobre aspectos exteriores podem ser vistas como conflitos mais profundos a respeito da compreensão do que efetivamente significa ser cristão. Nesse sentido, se, por um lado, é necessário reconhecer 
que não existe uma única forma de viver o cristianismo, por outro, é igualmente indispensável interpelar todas as formas de modo a que, no encontro e no diálogo, se respeitem, se interpelem e se purifiquem mutuamente.

A ação evangelizadora da Igreja no Brasil, em suas Diretrizes Gerais para o período 2011-2015, acentuava dois termos importantes para a compreensão do cristianismo em nossos dias. São expressões cujos conteúdos se encontramno no núcleo da mensagem cristã, assumindo, desse modo, relevância para os dias atuais, sem, contudo, perder a identidade primordial. Estas duas expressões são alteridade e gratuidade. Como atitudes ligadas ao conjunto da vida, apresentam-se acima da diversidade de linguagens ou formas, devendo estar presentes em todas as expressões do cristianismo, sigam estas expressões o estilo que seguirem. Mais do que a verificação se um grupo, por exemplo, reza no silêncio monacal ou através da glossolalia ruidosa, ambas linguagens, expressões, formatos, é necessário verificar até que ponto estes dois grupos, diametrais no formato, são capazes de estabelecer relacionamentos abertos, aptos à mutua interpelação rumo Àquele que ultrapassa todas as formulações.

A alteridade é a capacidade de reconhecer o outro como tal, diferente de mim, e que, por isso mesmo, me interpela em sua diferença, causando-me impacto, mas também fascínio, ratificando-me e me instando a me transformar, num processo bastante dinâmico. Trata-se da condição de ser efetivamente outro e não apenas reflexo, espelho, de mim mesmo. Por sua vez, a gratuidade é a condição de se abrir ao outro simples e exatamente por que ele(ela) é outro(a) e não porque dele(a) eu possa usufruir algo, como ocorre na lógica de mercado, em que as relações com as coisas atingem as relações com as pessoas. Consequentemente, alteridade e gratuidade se complementam, como partes de uma única realidade, de uma única resposta à questão do sentido, do significado da existência.

Um último aspecto a ser considerado na ação evangelizadora junto à(s) juventude(s) diz respeito à individualidade, tão valorizada desde o advento da modernidade. Nosso tempo, mais do que um período em que o sentido da existência é encontrado na tradição, ou seja, no que é transmitido pelas gerações anteriores, e conservado pelas instituições, vem se tornando um tempo em que o sentido se busca e se encontra em nível individual, pessoal. Já não se trata de sentidos predominantemente aceitos, acolhidos, mas de sentidos acima de tudo buscados, escolhidos. Passamos, deste modo, do acolhimento para a escolha, da aceitação para a opção. Assim como nos outros processos aqui descritos, também esta passagem é marcada pela ambiguidade. Por um lado, 
é negativa quando compreendida como individualidade não relacional. Por outro, é positiva quando valoriza a individualidade ou pessoalidade, trazendo para o centro da ação pastoral a atitude inalienável da escolha, concretizada no que, desde as origens tem marcado o cristianismo, que é a experiência de conversão. Como bem sabemos, a experiência cristã nasce de um encontro entre a graça e a pessoa, entre a proposta e a resposta. Estes dois polos de uma relação muito especial não podem ser eliminados nem ter suas partes substituídas. A eliminação se dá de modo grosseiro pelo simples e imediato descarte da outra parte, como se, no caso do indivíduo fechado em si, não houvesse abertura antropológica para a alteridade. De modo mais ameno, a eliminação se dá quando a outra parte deixa de ser vista como efetiva alteridade e o relacionamento se torna funcional ou interesseiro. A proposta se liga à primazia da graça e a resposta se liga, sob a ação da graça, à individualidade que não pode ser substituída por nenhuma outra instância. Emergem, deste modo, não apenas a importância do primado da graça de Deus, mas também a noção cristã de pessoa, com as características que a história do cristianismo adquiriu e acumulou no decorrer dos séculos. ${ }^{11}$

A partir do conceito de pessoa, o cristianismo, ainda que sob a variedade de linguagens e formas de concretização, defende o valor de cada ser humano, independentemente de qualquer outra condição que não seja o existir. A pessoa vale por si, em si e, por isso mesmo, não pode ser desrespeitada na sua busca e no seu encontrar do sentido para a existência. Ao mesmo tempo, a pessoa é sempre referida às outras pessoas, num processo de contínuo e escatológico encontro em que auto possessão e relacionalidade se completam, se articulam, buscando-se mutuamente. Na pessoa humana, individualidade e fraternidade coexistem, de modo que a efetiva maturidade acontece quando estes dois aspectos se vão encontrando e se ajudando de modo recíproco. Nem fechamento autossuficiente, nem anulação de si em função de outrem, mas equilíbrio na busca do sentido da existência.

É por isso que o Documento de Aparecida, em linha de continuidade com o expressado pelo Papa Bento XVI no discurso inaugural daquela Conferência, afirma que a experiência cristã não se inicia por uma decisão ética, ou seja, a partir do próprio eu que, de dentro do seu interior, isoladamente faz escolhas sem considerar a alteridade. A escolha é inegavelmente feita, mas ela acontece como resposta, momento segundo, decorrente da interpelação feita pela graça.

${ }^{11}$ RUBIO, A. G., Unidade na pluralidade, p. 303-317; 444-458. 
Os termos do Documento de Aparecida são, nesse sentido, bastante claros: "não se começa a ser cristão por uma decisão ética ou uma grande ideia, mas pelo encontro com um acontecimento, com uma Pessoa, que dá um novo horizonte à vida e, com isso, uma orientação decisiva". ${ }^{12}$ Utilizando os termos aqui mencionados, não se encontra o sentido da vida a partir unicamente de si mesmo(a), mas a partir do encontro com a Alteridade das Alteridades, cujo resultado é um novo significado para a existência. Portanto, nem o Documento de Aparecida nem o Papa Bento XVI removem da experiência cristã a resposta pessoal, mas a colocam no horizonte dialogal inerente ao Deus da Revelação e ao que essa mesma Revelação apresenta como pessoa.

O mesmo raciocínio aparece no magistério do Papa Francisco, com especial atenção para a Exortação Apostólica Gaudete et Exultate, lida junto com a Carta Placuit Deo, da Congregação para a Doutrina da Fé. Ambas tratam de duas questões que afetam muito diretamente a identidade do cristianismo e da pessoa, atuando, portanto, na concepção de sentido para a vida. São o pelagianismo e o gnosticismo. ${ }^{13}$ É verdade que estas duas palavras podem soar estranhas e mesmo irrelevantes para nossos dias, deixando a impressão de que se está batalhando por detalhamento doutrinal, linguagem, formulação, portanto, diante de um mundo com tantas dores e mortes. No entanto, é exatamente na base de todas essas dores e mortes, que se encontra o que o Papa Francisco tem chamado de globalização da indiferença. ${ }^{14}$

Há no pelagianismo e no gnosticismo duas atitudes que ferem diametralmente a alteridade, que agridem o reconhecimento do outro como tal. No pelagianismo, encontramos a prepotência de quem, no fundo, acredita apenas em si. No gnosticismo, além do desprezo pelo corpo e consequentemente desvalorização da encarnação e da história,${ }^{15}$ encontramos o risco de dividir a humanidade entre espiritualizados, isto é, os iniciados, e os não iniciados, em pessoas de categoria superior e de categoria inferior. Quando juntamos os dois, pelagianismo e gnosticismo, percebemos neles as bases filosóficas e antropológicas para um mundo de individualistas e de excludentes, um mundo onde as pessoas pensam apenas em si mesmas e onde a sociedade é estruturalmente dividida, devendo assim permanecer.

\footnotetext{
${ }^{12}$ DCE 1; DAp 12.

${ }^{13}$ GE 36-62; PD 3-4.

${ }^{14}$ EG 54.

${ }^{15}$ PD 4.
} 
Percebemos, assim, forte preocupação quanto à identidade da pessoa em linha de alteridade e gratuidade. A presença positiva do(a) outro(a), como condição de enriquecimento humano, como caminho de humanização ou, mais ainda, de co-humanização, é uma grande contribuição que o cristianismo tem a dar à(s) juventude(s) nosso tempo. Pode-se mesmo dizer que se trata da específica contribuição cristã, a partir da qual emergem os demais compromissos, neles incluindo os desafios socioambientais.

\section{Indicativos para uma ação pastoral junto à(s) juventude(s)}

Por tudo isso e fazendo a ressalva de que será necessário ouvir as contribuições sinodais e a exortação apostólica que poderá advir, é admissível auferir algumas indicações pastorais. Estas indicações se referem ao objetivo, ao ponto de partida e ao método a se considerar. Não são sugestões desconectadas do caminhar histórico da ação evangelizadora no Brasil e no mundo. Recolhem as contribuições do refletir pastoral pós-conciliar, com especial atenção para o que, desde João Paulo II, se convencionou chamar como nova evangelização, termo mantido por Bento XVI e que o Papa Francisco indica como "igreja em saída" rumo às periferias existenciais, ${ }^{16}$ dentre as quais se encontra a juventude. ${ }^{17}$

O objetivo da ação evangelizadora junto à(s) juventude(s) deve ser o do encontro do sentido da vida em Jesus Cristo ou, dito de modo inverso, o encontro de Jesus Cristo como sentido para a vida. Mais, portanto, do que uma ação evangelizadora de cunho informativo ou doutrinal, reitera-se a urgência de se possibilitar a compreensão do que podemos denominar como peculiaridade de Jesus Cristo, pessoa e mensagem, em torno da alteridade e da gratuidade, em vista da formação da pessoa integral, autônoma e relacional.

A insistência da questão do sentido da vida, além de encontrar sua motivação na mudança de época, fato que a torna validade para todas as fases da vida, torna-se ainda mais urgente quando se trata da(s) juventude(s). Isto acontece porque, além do processo natural de configuração da personalidade, a(s) juventude(s) de nosso tempo têm apresentado uma característica que vem adquirindo conotações de urgência e preocupação. Trata-se dos crescentes casos de suicídio em especial na faixa etária entre 15 e 29 anos. Embora

\footnotetext{
${ }^{16}$ EG 20, 30, 46.

${ }^{17}$ EG 64.
} 
se trate de uma questão complexa, com diversas vertentes e possibilidades de abordagem, não se pode negar que, entre os fatores, encontra-se o vazio existencial, a ausência de um significado para a existência. Ao lado da depressão, da ansiedade e de outras questões congêneres, o contato com as situações de violência, o uso de drogas e o enfraquecimento das instâncias de apoio, tais como a família, acabam por gerar o conhecido vazio existencial.

A primeira das indicações refere-se ao desafio de continuar anunciando Jesus Cristo. $\mathrm{O}$ "ide por todo o mundo e anunciai o evangelho a toda criatura ... quem crer e for batizado será salvo" (Mc 16,15) é um dado da Escritura, junto com a prática do amor, da solidariedade e da justiça. A questão pastoral, portanto, não consiste em deixar de anunciar, mas, na coerência com Aquele que é anunciado, significa não impor, não obrigar à força, seja física seja psicológica. Nem espadas nem manipulações, mas respeito. A consciência de uma identidade não pode transformar a pastoral em guerra santa. E, do outro lado, a tolerância não pode se transformar em omissão.

Este anúncio passa cada vez mais pelo testemunho pessoal. A modernidade valoriza bastante o indivíduo. A experiência cristã vai dizer que o indivíduo é importante, cada indivíduo e todos os indivíduos o são. Só não o são de modo fechado em si. Todos, ao mesmo tempo em que são valorizados, são igual e concomitantemente chamados a se abrir ao encontro com os outros, que possuem o mesmo valor. Para nós, cristãos e cristãs, o testemunho pessoal de abertura ao outro é o primeiro passo. Sem uma espiritualidade do testemunho pessoal, não venceremos os neopelagianismos e neo-gnosticismos desta segunda década do século XXI. Diante da fragilidade das instituições e das tradições, a missão se recompõe tendo como base o testemunho pessoal.

Em segundo lugar, destaca-se o desafio de se firmar a compreensão de Jesus Cristo como alteridade e gratuidade, cuja tradução pastoral consiste em testemunhar e anunciar Jesus Cristo a partir do horizonte do convívio, do diálogo e da fraternidade. As afirmações de identidade, com fanatismos pesados ou light, têm atribuído a Jesus forte conotação combativa, até mesmo bélica. É compreensível que, num tempo de frustrações diante da ineficácia das instâncias que deveriam produzir paz, justiça e concórdia, os corações humanos se voltem para a dimensão religiosa, nela buscando seu socorro. Só não podemos estimular leituras ou compreensões de Jesus Cristo com base na violência, no individualismo e na exclusão. Embora cientes de que compreensão alguma acerca de Jesus Cristo $\mathrm{O}$ esgota e, por isso mesmo, 
acolhemos e entendemos diferentes formulações, nem por isso devemos nos isentar de uma postura crítica em face a doses elevadas de belicosidade, as quais acabam por se tornar obstáculos para a vivência do amor, da alteridade e da gratuidade.

Em terceiro lugar, emerge a importância da Iniciação à Vida Cristã como uma atitude que transcende em muito os cursos para a recepção dos três sacramentos da iniciação cristã. É preciso voltar continuamente ao núcleo da mensagem de Jesus, buscando em sua pessoa e em sua mensagem a perspectiva de alteridade, uma alteridade tão forte e radical que ameaçava a compreensão que se tinha de Deus e da vida (Jo 11,50). Esta iniciação deve ser reiterada tantas vezes quantas necessárias, apresentando e reapresentando Jesus de modo trinitário, ou seja, numa perspectiva de alteridade. Na medida em que o momento existencial da juventude experimenta, em nossos dias, fragilidade quanto às identidades, torna-se fundamental que, a todo tempo, seja propiciado aos jovens o encontro com a Boa Nova. Este reiterar faz parte do atual momento histórico por que passa o mundo e, nele, a juventude. ${ }^{18}$

Em quarto lugar, encontramos o desafio da experiência eclesial. O Documento de Aparecida nos diz, ainda que com outras palavras, que os modos habituais de se fazer a experiência de Igreja têm encontrado dificuldade em responder satisfatoriamente às questões apresentadas por quem vive neste mundo em esgotamento. ${ }^{19}$ Dentre esses, podemos destacar os jovens. Isso acontece porque a experiência eclesial apresenta uma base antropológica indispensável, que é a relação de irmãos e irmãs. Nesse sentido, eclesiologia e antropologia se articulam. Humanamente falando, a experiência de Igreja se dá a partir do convívio fraterno, convívio que rompe as barreiras da indiferença, atualmente globalizada, do preconceito e da intolerância. A questão pastoral aqui consiste em reconhecer que, algumas das experiências eclesiais de nosso tempo, são muito mais fornecedoras de serviços do que efetivas possibilidades de comunhão e fraternidade. A configuração eclesial em torno das pequenas comunidades em rede é o caminho pastoral, onde a vida de irmãos e irmãs se torna testemunho a gerar fascínio e atração, dentro, por certo, de um clima de liberdade e respeito ao diferente..$^{20}$ Esta é a razão

\footnotetext{
${ }^{18}$ No Brasil, a Conferência Episcopal tratou especificamente do tema: CNBB, Doc. 107; MORAES, A. O., A catequese hoje, p. 263-276.

${ }^{19}$ DAp 172ss.

${ }^{20}$ CNBB, Doc 100, 11-61.
} 
antropológica pela qual os jovens de nosso tempo se sentem atraídos por experiências eclesiais fortemente centradas na fraternidade, com tudo o que essa fraternidade implica: acolhimento, identidade, resgate...

Em quinto, não há como deixar de lado o diálogo ecumênico e interreligioso. Aqui, importa destacar a importância do encontro - tanto ecumênico quanto inter-religioso - para a construção da paz. Se as diversas religiões conseguirem evitar dois perigos, já teremos dado vários passos. O primeiro perigo se encontra na imagem da "guerra santa", onde o combate, a agressão e o desrespeito podem chegar até à violência física. O segundo perigo, muito próximo do anterior, revela uma espécie de guerra comercial, em que o fechamento ao encontro ecumênico e inter-religioso se fundamenta e se concretiza em trabalho mercadológico por clientela, com seus dízimos e estipêndios. Essas duas atitudes, tomadas por quem quer que seja, agridem o autêntico espírito da alteridade e precisam ser superadas.

Já de longa data, o ecumenismo e o diálogo inter-religioso possuem um caminho muito fértil para acontecer. Trata-se do trabalho pela paz, pela justiça e pela solidariedade. A dor e a morte não têm religião. Atingem o ser humano independentemente de qualquer outra situação e, com isso, desafiam a todos. $\mathrm{O}$ ecumenismo e o diálogo inter-religioso em torno da caridade e da solidariedade vão permitir que se encontrem caminhos que ultrapassem os gabinetes, os púlpitos e as publicações. Vão mostrar que a prática direta e imediata de contato com sofredores da terra possui força suficiente para derrubar fanatismos e relativismos, fechamentos e relaxamentos, passando pela brecha estreita referida antes.

Em sexto lugar, deve-se considerar a prática da caridade, da solidariedade e da defesa da vida em todas as suas instâncias. Num tempo em que a crença em projetos não se mede tanto por suas justificativas teóricas, porém muito mais pela participação direta de cada um nas ações desenvolvidas, a(s) juventude(s) tendem a ser mais atraídas por propostas que lhes permitam colocar a mão na massa, sentindo concretamente que sua escolha está produzindo resultados. Esta certeza não brota de especulações ou formulações abstratas, mas predominantemente deste poder agir, deste ser parte direta nos processos e projetos. Deste modo, as grandes questões humanitárias de nosso tempo, com a amplitude socioambiental que apresentam, tornam-se campo fértil para o acolhimento da(s) juventude(s), em sua diversificação. 


\section{Conclusão}

Pensar, portanto, a(s) juventude(s) em nossos dias exige reconhecer que o mundo todo passa por uma mudança epocal. Nesta mudança, os jovens estão entre os que experimentam de modo mais intenso as fragilidades existenciais. São atingidas muito de perto pela debilidade das respostas à questão do sentido. Por esse motivo, dentro de um processo de diálogo com o mundo em aguda transformação, realizou-se o Sínodo da Juventude, cujas reflexões e posteriores orientações ajudarão ainda mais no caminhar pastoral católico.

Em todo esse processo, há de se reconhecer a importância do que denominamos como base antropológica, ou seja, o reconhecimento do(a) jovem e de todo ser humano como pessoa, com insubstituível valor em si e ao mesmo tempo aberta aos demais seres humanos e à criação como um todo. Consequentemente, mais do que trabalhar com a(s) juventude(s) a partir de uma perspectiva doutrinarizante, importa ajudar na solidificação desta condição humana e co-humana, iluminando-a com a Boa Nova do Reino de Deus. Não serão, por certo, duas atividades justapostas, a que aborda o dado humano e a que aborda o dado da Revelação. Trata-se de uma única história, em que, fortalecendo-se a base humana, cria-se terreno fértil para o anúncio do Evangelho, em que trabalhando junto à questão do sentido da vida, se fortalece a compreensão de toda a vida como vocação e missão.

\section{Referências bibliográficas}

ABRAMO, H. W.; FREITAS, M. V; SPOSITO, M. P. Juventude em debate. São Paulo: Cortez, 2000.

BAUMAN, Z. O mal-estar da pós-modernidade. Rio de Janeiro: Zahar, 1997.

BENEVIDES, S. C. O. Na contramão do poder. Juventude e movimento estudantil. São Paulo: Annablume, 2006.

BENTO XVI, PP. Deus Charitas Est. Disponível em: $<$ http://w2.vatican.va/ content/benedict-xvi/pt/encyclicals/documents/hf_ben-xvi_enc_20051225_ deus-caritas-est.html>. Acesso em: 19 jul. 2018.

BERGER, P. L.; GORDON, F. O Imperativo Herético - Possibilidades Contemporâneas da Afirmação Religiosa. Petrópolis: Vozes, 2017. 
CELAM. Documento de Aparecida. Texto conclusivo da V Conferência Geral do Episcopado Latino Americano e do Caribe. Brasília: Edições CNBB; São Paulo: Paulus / Paulinas, 2007.

CNBB. Comunidade de Comunidades: uma nova paróquia. Brasília: Edições, 2014. (Doc. 100).

CNBB. Iniciação à Vida Cristã: itinerário para formar discípulos missionários. Brasília: Edições CNBB, 2017. (Doc. 107).

CONGREGAÇÃO PARA A DOUTRINA DA FÉ. Carta Placuit Deo sobre alguns aspectos da salvação cristã, de 22 de fevereiro de 2018. Disponível em: <http://www.vatican.va/roman_curia/congregations/cfaith/documents/rc con_cfaith_doc_20180222_placuit-deo_po.html>.Acesso: 23 jul. 2018.

DEVERSON, J.; HAMBLETT, C. Generation X. Londres: Universal-Tandem, 1964.

FRANCISCO, PP. Exortação Apostólica Evangelii Gaudium. Disponível em: < http:/w2.vatican.va/content/francesco/pt/apost_exhortations/documents/ papa-francesco_esortazione-ap_20131124_evangelii-gaudium.html >. Acesso em: 18 jul. 2018.

FRANCISCO, PP. Exortação Apostólica Gaudete et Exultate. Disponível em: <http://w2.vatican.va/content/francesco/pt/apost_exhortations/documents/ papa-francesco_esortazione-ap_20180319_gaudete-et-exsultate.html $>$. Acesso em: 18 jul. 2018.

MORAES, A. O. A catequese hoje: reflexões teológico-pastorais a partir da Evangelii Gaudium. In: AMADO, J.; FERNANDES, L. (Orgs.). Evangelii Gaudium em questão: aspectos bíblicos, teológicos e pastorais. São Paulo: Paulinas; Rio de Janeiro: Editora PUC-Rio, 2014. p. 263-276.

PALFREY, J.; GASSER, U. Nascidos na era digital. Entendendo a primeira geração de nativos digitais. Porto Alegre: Artmed, 2011.

PRADO, A. R. (Org.). Cultura juvenil: perspectivas e desafios para os novos tempos. São Paulo: Paulus, 2014.

RUBIO, A. G. Unidade na pluralidade. O ser humano à luz da fé e da reflexão cristãs. São Paulo: Paulus, 2001.

SILVA, W. T.; ROCHA, D. Os anos 1960 e o horizonte utópico da juventude católica. Atualidade Teológica, v.22, n.60, p. 623-643, set./dez. 2018. 
Disponível em: <https://www.maxwell.vrac.puc-rio.br/35786/35786. PDFXXvmi=>. Acesso em: 06 jan. 2019.

SÍNODO DOS BISPOS. Documento final da Reunião Pré-sinodal. Disponível em: <http://www.synod2018.va/content/synod2018/pt/ apresentacao-della-reuniao/documento-final-da-reuniao-pre-sinodal. html>. Acesso em: 17 jul. 2018.

SÍNODO DOS BISPOS. Os jovens, a fé e o discernimento vocacional. Documento preparatório à XV Assembleia Geral Ordinária do Sínodo dos Bispos. Disponível em: <http://www.vatican.va/roman_curia/synod/ documents/rc_synod_doc_20170113_documento-preparatorio-Xv_po.html> Acesso em: 23 jul. 2018.

ULRICH, J. M.; HARRIS, A. L. GenXegesis: Essays on alternative youth (sub)culture. Madison: WUP, 2003.

VARGAS GIL SOUZA, C. Z. Juventude e contemporaneidade: possibilidades e limites. Última década. Disponível em: <https://scielo.conicyt.cl/scielo. php? script $=$ sci_arttext\&pid=S0718-22362004000100003\&lng=es\&nrm=iso $>$. Acesso: 19 jul. 2018.

Joel Portella Amado

Doutor em Teologia pela Pontifícia Universidade Católica do Rio de Janeiro Docente de Teologia na Pontifícia Universidade Católica do Rio de Janeiro Rio de Janeiro / RJ - Brasil E-mail: joelamado@puc-rio.br

Recebido em: 29/10/18

Aprovado em: 10/02/19 